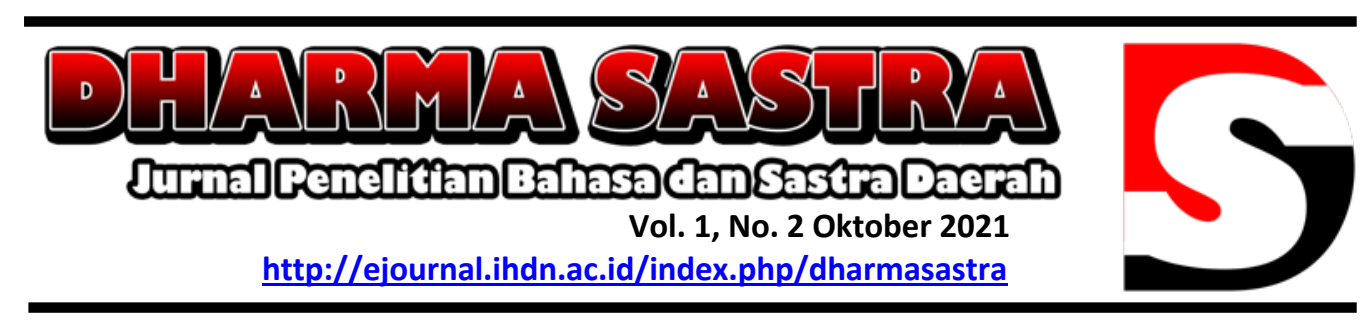

\title{
Pentingnya Pembelajaran Sor Sing gih Bahasa Bali Sebagai Budaya Bali Bagi Siswa SD
}

\author{
Ketut Susiani \\ Universitas Pendidikan Ganesha, Email: ketut.susiani@undiksha.ac.id
}

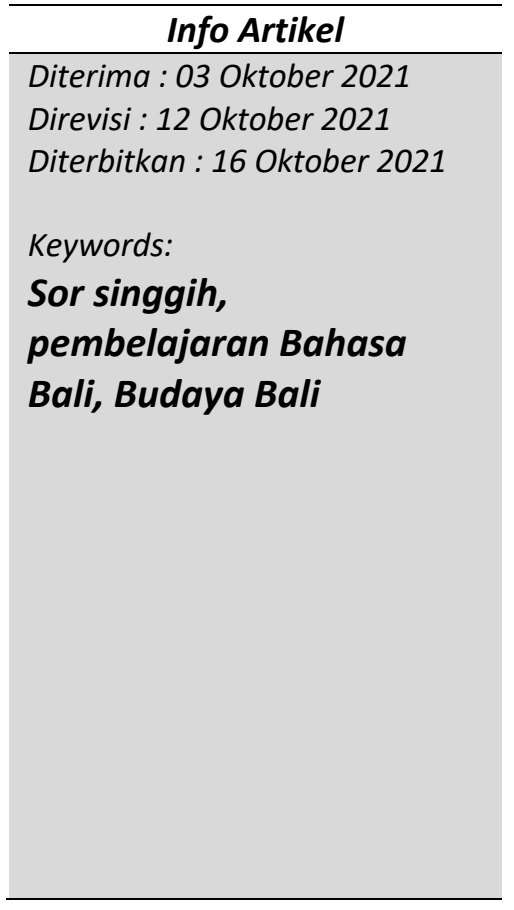

\begin{abstract}
The Balinese language is historical evidence for Balinese people who are domiciled as a vehicle for Balinese cultural expression, in which aesthetic, religious, social, political, and other aspects of Balinese life are recorded. The Balinese language is one of the regional languages that has a multi-level language system (anggah-ungguhing basa/sor singgih basa Bali). The purpose of this study was to provide elementary school students with an understanding of the importance of learning the Balinese language asSor Singgih as Balinese culture. The method used in this study is a qualitative method with interview and observation techniques. The results of this research are that it is important for us to teachSor Singgih Balinese language to students, in addition to communicating with other people, we can also introduce the culture of the Balinese language to others. this can be done by using a short storybook, sample stories can make it easier for students to understandSor Singgih Balinese language.
\end{abstract}

\section{Pendahuluan}

Bahasa Bali adalah salah satu bahasa daerah di negara Indonesia yang dipelihara dengan baik oleh masyarakat penuturnya, yaitu etnis Bali. Bahasa Bali sebagai bahasa ibu atau bahasa pertama bagi sebagian besar masyarakat Bali, dipakai secara luas sebagai alat komunikasi dalam berbagai aktivitas di dalam rumah tangga dan di luar rumah tangga yang mencakupi berbagai aktivitas kehidupan sosial masyarakat Bali. Oleh karena itu, bahasa Bali merupakan pendukung kebudayaan Bali yang tetap hidup dan berkembang di Bali. Keberadaan bahasa Bali memiliki variasi yang cukup rumit karena adanya sor-singgih yang ditentukan oleh pembicara, lawan bicara, dan hal-hal yang dibicarakan. Secara umum, variasi bahasa Bali dapat dibedakan atas variasi 
temporal, regional, dan sosial. Dimensi temporal bahasa Bali memberikan indikasi kesejarahan dan perkembangan bahasanya meski dalam arti yang sangat terbatas. Secara temporal bahasa Bali dibedakan atas bahasa Bali Kuno yang sering disebut dengan bahasa Bali Mula atau Bali Aga, bahasa Bali Tengahan atau Kawi Bali, dan bahasa Bali Kepara yang sering disebut Bali Baru atau bahasa Bali Modern. Senada dengan (Suasta, 1997) ada tingkatan-tingkatan Bahasa Bali jika dilihat dari perkembangannya yang disebut denganSor Singgih bahasa Dalam perkembangannya muncul tingkatan-tingkatan bahasa dalam bahasa Bali yang disebutSor Singgih bahasa Bali. Stratifikasi tersebut terdiri atas dua jenis yaitu: stratifikasi masyarakat suku Bali tradisional dan stratifikasi masyarakat suku Bali modern (Putu \& Adnyana, n.d.). Bahasa Bali memiliki dua dialek utama, dialek Bali dataran rendah (dialek BD) dan dialek Bali Gunung (dialek BA). Dialek Bahasa daerah memiliki bentuk penghormatan yang sistematis yang terutama didasarkan pada perbedaan kasta antar penutur dalam masyarakat (Hara Mayuko, 2015)

Secara regional, bahasa Bali dibedakan atas dua dialek, yaitu dialek Bali Aga (dialek pegunungan) dan dialek Bali Dataran (dialek umum, lumrah) yang masing-masing memiliki ciri subdialek tersendiri. Berdasarkan dimensi sosial, bahasa Bali mengenai adanya sistemsor-singgih atau tingkat tutur bahasa Bali yang erat kaitannya dengan sejarah perkembangan masyarakat Bali yang mengenal sistem wangsa (warna), yang dibedakan atas golongan triwangsa (Brahmana, Ksatriya, Wesia) dan golongan Jaba atau Sudra(orang kebanyakan). Berdasarkan strata sosial ini, bahasa Bali menyajikan sejarah tersendiri tentang tingkat tutur kata dalam lapisan masyarakat tradisional di Bali. Disisi lain (nengah Duija, 2007) mengatakan bahwa bahasa Bali memiliki sisitem yang bertingkat-tingakat atau yang sering disebut dengan anggahungguhin basa/sor singgih Bahasa Bali.

Dalam kehidupan sehari-hari (Sujana, 2017), Bahasa yang digunakan sebagai alat komunikasi oleh suku Bali adalah Bahasa yang bersifat tradisional maupun bersifat modern, karena keduanya memiliki makna atau pengaruh yang besar dan kuat terhadap sopan santun dalam berkomunikasi.

Jika kita lihat perkembangan IPTEK saat ini sangatlah cepat apalagi saat ini kita berada pada abad 21 dengan revolusi 4.0. hal ini menandakan dalam dunia pendidikan memberikan tantangan pada para pendidik untuk mengembangkan kemampuannya dalam membelajarkan pebelajar dengan memanfaatkan IPTEK yang semakin pesat. Dengan adanya teknologi pendidik mampu mengembangkan media pembelajaran, materi ajar dan berbagai sarana belajar dalam membelajarkan peserta didik, terutama dalam mata pelajaran Bahasa Bali.

Basa Bali Sor Singgih adalah bahasa Bali yang dipergunakan ketika kita menghormati lawan bicara ataupun kepada orang yang patut kita hormati seperti Ida anak lingsir, Ida anaké agung, tokoh agama, pemimpin pemerintahan, maupun yang lainny. (Andini, 2019) upaya dalam mendukung kelestarian dan keajengan basa Bali sebagai identitas daerah Bali diwajibkan untuk diajarkan di sekolah pada jenjang Pendidikan untuk menghindari kepunahan Bahasa Bali sebagai bahasa daerah masyarakat Bali.

Dilihat dari Permen 22 tahun 2003, Pendidikan bisa dijadikan suatu wadah dalam pembentukan perilaku dan karakter manusia dimulai dengan menanamkan Bahasa Bali 
sejak dini. Salah satu contoh yang bisa dilakukan adalah dengan menjadikan Bahasa Bali sebagai mata pelajaran di sekolah. (Sidang, 2021) Dalam pelaksanaanya bahasa Bali tidak bisa lepas dari bahasa, aksara dan sastra Bali, dan empat keterampilan berbahasa yaitu: keterampilan menyimak (mendengarkan), keterampilan berbicara, keterampilan membaca dan keterampilan menulis.

Jika dilihat dari fenomena tersebut adalah siswa SD saat ini masih mengalami kesulitan untuk menyampaikan gagasan dan perasaannya dalam Sor Singgih bahasa Bali yang tepat. Dengan permasalahan tersebut perlu penguasaan Sor Singgih bahasa Bali dalam keterampilan berbicara dan perlu diketahui bahwa pentingnya pembelajaran Sor Singgih bahasa Bali bagi siswa SD dan masyarakat secara umum.

\section{Metode}

Metode yang digunakan dalam penelitian ini adalah metode kualitatif deskriptif dan pengumpulan data melalui observasi dan wawancara. Menurut Moleong (2021) penelitian kualitatif merupakan prosedur dalam penelitian yang menghasilkan data deskriptif berupa kata-kata tertulis ataupun lisan dari perilaku orangorang yang dapat diamati. Penggumpulan data melalui observasi untuk mengetahui lingkungan di sekolah untuk mengetahui pembelajaran Sor Singgih bahas Bali bagi siswa SD dan pentingnya pembelajaranSor Singgih bahasa Bali sebagai budaya Bali. Serta melalui wawancara dengan masyarakat disekolah untuk menggumpulkan data-data yang diperlukan. Adapun tahapan observasi dan wawancara yang dilakukan adalah dilihat dari pentingnya Pembelajaran Sor Singgih Bahasa Bali Bagi Siswa SD; Untuk mengetahui proses pembelajaran yang dilakukan guru dalam mengajarkan Sor Singgih bahasa Bali bagi siswa SD, peneliti melakukan perekaman terhadap proses pembelajaran. Setelah itu, peneliti melakukan analisis terhadap perangkat pembelajaran yang dipakai oleh guru saat pembelajaran berlangsung. Analisis perangkat pembelajaran tersebut meliputi analisis kurikulum, analisis silabus, rencana pelaksanaan pembelajaran, media pembelajaran, dan evaluasi yang dilakukan oleh guru mata pelajaran bahasa Bali.

\section{Pembahasan}

Berdasarkan hasil observasi dan wwawancaa yang di lakukan di sekolah dasar menunjukkan bahwa Terkait dengan materi pembelajaran, materi seharusnya dipilih dan disajikan untuk mendukung kompetensi dasar dan indikator yaitu memahami dan bagaimana ciri-ciri Sor Singgih basa Bali. Guru belum menyajikan materi di dalam RPP yang dimana seharusnya ditulis dalam butir-butir materi yang sesuai dengan indikator ketercapaian kompetensi. Materi pembelajaran juga semestinya akurat sesuai dengan materi dan tidak salah konsep yaitu mengenai Sor Singgih bahasa Bali dan klasifikasinya. Menurut salah satu guru mengatakan bahwa hal ini diakibatkan karena pembelajaran dilakukan secara daring sehingga menerapkannya sulit sesuai dengan RPP dan silabus. 
Adapun pembahasan lebih terperinci sebagai berikut, ada RPP tertera dalam kegiatan pendahuluan diawali dengan mengucapkan salam panganjali "Om Swastyastu". Kegiatan mengucapkan salam panganjali merupakan salah satu kegiatan pembelajaran sikap religious walaupun kegiatan berdoa tidak dilakukan oleh guru. Hal ini dikarenakan salam panganjali "Om Swastyastu", tidak hanya merupakan salam tetapi juga doa. Kegiatan yang dilakukan guru selanjutnya adalah menyiapkan peserta didik secara fisik dan psikis untuk mengikuti proses pembelajaran. Sebelum memasuki kegiatan inti yakni menyampaikan materi terkaitSor Singgih bahasa Bali, terlebih dahulu guru guru mengaitkan pembelajaran yang akan dipelajari dengan mengajukan beberapa pertanyaan yang berkaiatan dengan pembelajaran yang akan diikuti oleh siswa.

Kegiatan pembelajaran yang dilakukan guru pada kegiatan inti mengacu pada langkah-langkah yang sudah direncanakan dalam RPP. Kegiatan inti ini diawali oleh guru dengan memberikan penjelasan terkait materi Sor Singgih bahasa Bali, meski dalam RPP tidak dicantumkan guru tersebut harus menyampaikan materi terlebih dahulu. Pada kegiatan mengamati guru memfasilitasi siswa menyimak pemaparan materi yang diberikan oleh guru. Setelah guru menyelesaikan materinya, barulah beberapa siswa diberikan kesempatan untuk membacakan contoh percakapan yang diberikan oleh guru. Selanjutnya, siswa diberikan tugas untuk mecari tahu bahasa halus apa yang terdapat dalam percakapan tersebut beserta contoh katanya. Dalam hal ini guru sangat menguasai Kelas, sehingga siswa mau berperan aktif dalam proses belajar mengajar ini. Selanjutnya beberapa siswa diberikan kesempatan untuk menyampiakan bahasa apa yang terkandung dalam percakapan tersebut disertai dengan mengapresiasi jawaban siswa. Setelah itu, barulah siswa diberikan tugas untuk membuat percakapan yang mengacu pada Sor Singgih bahasa Bali dengan teman sebangkunya yang akan dibacakan di depan Kelas oleh beberapa siswa yang ditunjuk oleh guru. Dalam hal ini guru sangat menguasai materi Sor Singgih bahasa Bali, hal ini terlihat ketika guru mengajar tanpa melihat refrensi yang digunakan.

Melihat aktivitas siswa dalam kegiatan pembelajaran, secara tidak langsung siswa sudah mengetahui bahwa penggunaan basa Bali Sor Singgih itu penting dilakukan atau diterapkan. Dengan mempelajari basa Sor Singgih sejak dini, maka kedepan sebagai generasi penerus bangsa mampu menjaga kelesatarian budaya Bahasa Bali. Manfaat yang bisa diperoleh siswa dalam belajar mengenal dan menerapkan basa BaliSor Singgih ini sangat penting seperti misalnya siswa mampu memberikan darma wacana dengan menggunakan basa Bali Sor Singgih, mampu berbicara basa Bali Sor Singgih baik dengan masyarakat Bali dengan kasta rendah maupun masyarakat Bali kasta tinggi. Bahasa Bali dan Sor Singgihnya mempunyai fungsi yang sangat penting antara lain sebagai lambang kebangaan daerah Bali, sebagai sarana penghubung berkomunikasi masyarakat Bali, sebagai identitas daerah masyarakat Bali, sebagai pendukung sastra daerah dan sastra Indonesia, dan sebagai pendukung budaya daerah dan budaya nasional. Dan menurut (Nuadiana, 2021) bahasa Bali juga diharapkan dapat mempertahankan taksu Bali.

Penelitian yang dilakukan Eka Ariathi (2010) menunjukkan bahwa 1) penggunaanSor Singgih Basa Bali dalam proses komunikasi pada STT Darma Bhuana cukup baik, karena hanya digunakan pada acara tertentu saja, (2) faktor yang menyebabkan STT Darma Bhuana sulit menerapkan Sor Singgih Basa Bali adalah faktor eksternal dan faktor 
internal yang meliputi faktor biologis dari keadaan anggota dan faktor psikologis juga mempengaruhi apabila dalam tubuh dan pemikiran mereka terjadi suatu kendala, maka secara langsung mempengaruhi juga pemakaianSor Singgih Basa Bali ini. (3) upayaupaya yang dapat dilakukan untuk meningkatkan pemahaman dan menerapkanSor Singgih Basa Bali dalam proses komunikasi antara lain: (a) peran dari orang tua untuk melatih dan mendidik anak sejak dini dengan memberikan pemahaman tentangSor Singgih Basa Bali dan kepada siapa anak tersebut harus mesor singgih basa Bali, (b) peran guru dalam mengupayakan pelajaran bahasa Bali khususnyaSor Singgih Basa Bali dengan memberikan motivasi belajar kepada anak didik dengan menggunakan bahasa alus sebagai bahasa pengantar di dalam proses pembelajaran (c) peran dari pemerintah dan lembaga adat untuk mendorong dan memfasilitasi generasi muda dalam upaya membina dan mengembangkan bahasa Bali khususnyaSor Singgih Basa Bali dalam perbuatan nyata.

Senada dengan penelitian yang dilakukan Melda Andini (2019) mengatakan bahwa penggunaan Sor Singgih basa Bali yang kurang tepat digunakan dalam cerpen berbahasa Bali siswa. Selanjutnya penelitian yang dilakukan Wirawan (2018), menunjukkan bahwa Hasil pengukuran motivasi belajar siswa menunjukkan bahwa motivasi belajar bahasa Bali Anggah - Ungguhing menggunakan kamus handphone berada pada kategori positif. Hal tersebut Nampak bahwa sarana prasarana menunjang keberhasilan siswa dalam belajar basa Bali Sor Singgih. Selanjutnya (Sujana, 2017) dalam proses pembelajaran bahasa Bali hendaknya guru menyeimbangkan penggunaan Bahasa diantara Bahasa kapare dengan Bahasa Sor Singgih, sehingga siswa mampu meresapi makna dari kata yang di ungkapkan. (Sujana,2017) juga menyampaikan bahwa penggunan Bahasa BaliSor Singgih mampu menanamkan sikap kesopan santunan sejak dini yang nantinya akan berdampak dalam upaya pembentukan karakter siswa.

Dilihat dari hasil penelitian yang dikemukan oleh beberapa peneliti tersebut dapat disimpulkan bahwa penggunaan basa Bali Sor Singgih sangat penting untuk dipelajari dan terapkan dan pembelajarannya disesuaikan dengan karakteristik, media yang digunakan serta sarana prasarana yang mendukung pembelajaran basa Bali Sor Singgih di sekolah dasar karena memiliki makna dalam pembentukan karakter siswa.

\section{Kesimpulan}

Guru dapat menggunkan media pembelajaran saat proses pembeajaran Sor Singgih, contohnya memberikan gambaran atau video pembelajaran agar peserta didik dapat memahami materiSor Singgih, untuk media berupa gambar contohnya, gambar yang berisikan tulisanSor Singgih dan artinya, serta video pembelajaran berupa animasi agar pembelajaran lebih menyenangkan dan siswa dapat memahami materiSor Singgih basa Bali. Basa BaliSor Singgih juga bisa diterapkan dengan sering berkomunikasi menggunakan basa BaliSor Singgih baik dilingkungan sekolah maupun di masyarakat. Dengan digunakannya basa BaliSor Singgih dalam komunikasi akan menjadi habit sehingga makna akan pentingnya penggunaan basa BaliSor Singgih secara tidak langsung dapat kita temukan. Selain itu Dengan menggunakan media pembelajaran yang digunakan baik berupa media visual maupun audio visual dapat membuat peserta didik 
lebih aktif dalam belajarSor Singgih bahasa Bali dan lebih mudah berkomunikasi dengan teman sebaya atau orang lain. Manfaat menggunakan media tersebut dapat memudahkan siswa dalam proses pembelajaran dan mudah di pahami oleh siswa sehingga tujuan dalam mengimplentasikan Bahasa Sor Singgih Bahasa Bali dapat diterapkan dengan baik dan memahami pentingnya Bahasa Sor Singgih untuk kita pelajari sejak dini untuk menjaga budaya Bali dan melestarikannya. Selain itu Bahasa Bali sebagai salah satu bahasa dan perekam budaya Bali sangat penting untuk dipelihara.

\section{Daftar Pustaka}

Adnyana, P. P. P. Pembelajaran Keterampilan Berbicara dalam PenggunaanSor Singgih Bahasa Bali (Doctoral dissertation, Udayana University).

Andini, N. P. M., Riana, I. K., \& Dhanawaty, N. M. (2019). PENGGUNAANSor Singgih BASA BALI PADA CERPEN BERBAHASA BALI SISWA SMP NEGERI 5 DENPASAR. Jurnal IImu Sosial dan Humaniora, 8(2), 105-111.

Ariathi, Eka. Dkk. 2010 PENGGUNAAN SOR SINGGIH BASA BALI DALAM KOMUNIKASI PADA STT DARMA BHUANA BANJAR TELUNWAYAH DUURAN, DESA TRI EKA BHUANA, SIDEMEN, KARANGASEM. Tersedia pada; file://C:/Users/admin/AppData/Local/Temp/adoc.pub_penggunaan-sorsinggih-basa-Bali-dalam-komunikasi-.pdf Denpasar : Sari Kahyangan.

Dhanawaty, N. M. (2017). Perlunya Pembelajaran Bahasa Bali Yang Rekreatif Di Sekolah Dasar Multikultural Dan Multilingual. Madah: Jurnal Bahasa dan Sastra, 4(2), 120-130.

Duija, I Nengah. 2007. Aksara, Bahasa, dan Aksara Bali (Sebuah Pengantar).

Iskandarwassid dan Dadang Sunendar. 2009. Strategi Pembelajaran Bahasa. Bandung: PT. Remaja Rosdakarya.

Karepun, M. K. (2007). Mengurai Benang Kusut Kasta. Membedah Kiat Pengajegan Kasta di Bali.

Mayuko, H. (2015). "BENTUK HORMAT" DIALEK BAHASA BALI AGA DALAM KONTEKS AGAMA. Linguistik Indonesia, 33(2), 121-134.

Moleong, L. J. (2021). Metodologi penelitian kualitatif. PT Remaja Rosdakarya.

Nuadiana, I. N. (2021)'121' ‘. PEMERTAHANAN BAHASA BALI SEBAGAI BAGIAN PELESETARIAN KEARIFAN LOKAL. Widyadari: Jurnal Pendidikan, 22(1), 217-228.

Partayasa, K. S., Selasih, N. N., \& Sudarsana, I. K. (2021). STRATEGI PENYULUH BAHASA BALI DALAM MENINGKATKAN KETERAMPILAN BERBAHASA BALI PADA SISWA SEKOLAH DASAR DI DESA BESTALA BULELENG. PANGKAJA: JURNAL AGAMA HINDU, 24(1), 119-129.

Permen nomor 22 tahun 2003. Tentang sistem Pendidikan nasional.

Suasta, I. M. (1997). Berpidato dengan bahasa Bali. Jurusan Sastra Daerah, Fakultas Sastra, Universitas Udayana.

Sujana, W. (2017). PEMBELAJARANSor Singgih BAHASA BALI DALAM KETERAMPILAN BERBICARA DI KELAS VII SMP NEGERI 1 TABANAN, TAHUN PELAJARAN 2016/2017. Jurnal Imiah Pendidikan dan Pembelajaran, 1(1). 
Suwendi, I. M. (2014). MENUJU BAHASA BALI YANG HUMANIS (Reinterpretasi SorSinggih Bahasa Bali). Widyasrama, 24(2).

Warna, I Wayan, dkk.,1993, Ejaan Bahasa Bali yang Disempumakan (Huruf latin) Dinas Pengajaran Propinsi Daerah Tingkat I Bali, Denpasar.

Wirawan, I., \& Ludy Paryatna, I. B. M. (2018). The Development of an Android-Based Anggah-Ungguhing Balinese Language Dictionary. International Journal of Interactive Mobile Technologies, 12(1). 